\title{
JAGUNG (Zea mays) SEBAGAI TANAMAN SELA PADA PERKEBUNAN KARET (Hevea brasiliensis)
}

\author{
WILLIS ARNIATI \\ 1554201048 \\ Program Studi Agribisnis, Fakultas Pertanian, Universitas Lancang Kuning, \\ Pekanbaru, Indonesia. \\ e-mail: nounawillis18@gmail.com
}

\begin{abstract}
ABSTRAK
Penanaman karet sistem tumpang sari dapat membantu petani karet rakyat menghadapi masa tidak produktifnya tanaman karet ( 4 - 5 tahun ). Penanaman karet tumpang sari dapat meningkatkan produktivitas per satuan lahan karet yang dikelola petani, selain itu juga berpeluang mendukung program pemerintah dalam rangka swasembada pangan nasional. Penanaman karet tumpangsari harus direncanakan sejak awal agar tidak terjadi persaingan penyerapan unsur hara. Penanaman karet pola tumpangsari dapat juga dilakukan dengan tanaman pangan selain tanaman tahunan penghasil kayu, obat obatan. Komoditi pangan yang umum ditanam tumpang sari dengan tanaman karet adalah padi gogo, jagung, kacang kacangan dan tanaman hortikultura.
\end{abstract}

Kata kunci : Jagung, Tanaman Sela, Karet

\section{PENDAHULUAN}

Produksi jagung nasional tahun 2016 sebesar 23,58 juta ton sedangkan kebutuhan jagung nasional sebesar 16,30 juta ton (Pusdatin 2016). Dari data tersebut, Indonesia seharusnya surplus jagung sebesar 7,28 juta ton. Namun Indonesia masih impor jagung sebesar 2,40 juta ton, karena kebutuhan jagung untuk industri pakan sebesar 8,90 juta ton (BPS 2016).

Produksi jagung dapat ditingkatkan melalui peningkatan produktivitas dan perluasan pertanaman jagung. Peningkatan produksi jagung melalui peningkatan produktivitas relatif berjalan lambat. Oleh karena itu, perluasan pertanaman jagung merupakan pilihan cepat 
untuk peningkatan produksi jagung. Namun saat ini alih fungsi lahan tanaman pangan ke tanaman perkebunan semakin meningkat, petani di daerah Riau lebih memilih perkebunan sawit di bandingkan hanya menanam tanaman pangan.

Selama tanaman karet belum menghasilkan (TBM) kondisi tajuk belum menutup, dan akan menutup pada umur 4-5 tahun. Kondisi tersebut memungkinkan untuk memanfaatkan lahan di antara tanaman karet untuk pengusahaan bisnis lain, misalnya penanaman tanaman sela (intercroping) maupun peternakan. Pengusahaan ini diharapkan dapat meningkatkan produktivitas lahan perkebunan karet sekaligus menguatkan sektor pertanian terutama komoditi tanaman pangan melalui ekstensifikasi lahan pertanian dengan memanfaatkan areal TBM karet.

\section{TINJAUAN PUSTAKA}

Salah satu usaha yang dapat dilakukan untuk meningkatkan produksi tanaman jagung adalah dengan memilih sistem pola tanam yang tepat. Sistem pola tanam dapat dilakukan dengan monokultur atau polikultur. Penanaman secara monokultur dirasakan kurang menguntungkan karena mempunyai resiko yang besar, baik dalam keseimbangan unsur hara yang tersedia, maupun kondisi hama penyakit dapat menyerang tanaman secara eksplosif sehingga menggagalkan panen (Sutoro, et al., 1998).

Intensitas cahaya adalah banyaknya energi yang diterima oleh satu satuan tanaman per satuan luas dan per satuan waktu (kal/cm2/hari). Pengaruh intensitas cahaya terhadap pertumbuhan dan perkembangan tanaman sejauh mana berhubungan erat dengan fotosintesis (Surtinah, 2010). Jangung merupakan tanaman $C_{4}$ yang membutuhkan cahaya matahari penuh untuk Fotosintesis dan suhu optimal fotosintesa $30-45^{\circ} \mathrm{C}$ (Surtinah, 2010).

Laju fotosintesis tanaman kerdil lebih rendah dibandingkan laju fotosintesis tanaman yang tumbuh lebih baik dengan produksi tongkol yang tinggi. Hal ini disebabkan penyerapan unsur hara lebih rendah pada jagung yang mendapat naungan. (Ferry, et al., 2013). Pertumbuhan tanaman yang hidup menggunakan karbohidrat untuk respirasinya tergantung pada imbangan fotosintesis, yang membangun karbohidrat dan bahan tanaman dan respirasi yang menguraikan karbohidrat. Kalau fotosintesis melebihi respirasi, seperti yang lazim terjadi pada tanaman yang sedang tumbuh, akan terjadi pertumbuhan. Akan tetapi pada kondisi yang kurang cahaya, respirasi mungkin sama dengan fotosintesis dan pertumbuhan akan terhambat. 
Penerapan pola penanaman sistem tumpang sari sangat dipengaruhi oleh pengaturan jarak tanam (densitas) dan pemilihan varietas.

Menurut (Sitompul, et al., 1995) pengaturan jarak tanam merupakan salah satu cara untuk menciptakan faktor-faktor yang dibutuhkan tanaman dapat tersedia bagi setiap tanaman dan mengoptimalisasi penggunaan faktor lingkungan yang tersedia. Pada periode tertentu tanaman sangat sensitif dan peka terhadap kompetisi sehingga dapat mempengaruhi pertumbuhan dan hasil tanaman tersebut, namun persaingan dapat ditekan sekecil mungkin, dengan cara mengatur sumberdaya yang diperlukan untuk pertumbuhan tanaman tersebut. (Herlina 2011 dalam Surtinah; Susi, N ; Lestari, S, U).

Kendala pengembangan jagung di bawah tegakan tanaman karet adalah jenis tanah yang didominasi oleh Podsolik Merah Kuning dengan lapisan atas (top soil) sangat tipis antara 5$15 \mathrm{~cm}$, miskin bahan organik, miskin hara $\mathrm{N}, \mathrm{P}, \mathrm{K}, \mathrm{Mg}, \mathrm{Ca}$, kemasaman tinggi ( $\mathrm{pH}$ rendah), karena kadar alumunium ( $\mathrm{Al})$ dan besi $(\mathrm{Fe})$ tinggi yang sangat menghambat pertumbuhan akar tanaman. Jenis tanah di Riau didominasi oleh Podsolik Merah Kuning (PMK) yang dikenal mengandung sedikit unsur hara, sedikit mengandung bahan organik, dan $\mathrm{pH}$ yang rendah (Surtinah, 2012).

Meningkatkan ketersediaan unsur hara dalam tanah dan khususnya untuk memperbaiki kesuburan kimia dan biologi pada tanah lahan gambut merupakan alternatif yang tepat, hal ini sejalan dengan kebijakan yang dipilih dalam budidaya tanaman yakni efisiensi energi dan selaras dengan lingkungan (Suriadikarta, Ardi, Simanungkalit dalam Susi, N; Surtinah; Rizal, M., 2018).

\section{HASIL DAN PEMBAHASAN}

Teknologi tanaman sela atau tumpangsari di antara tanaman karet akan memberikan manfaat : (1) efisiensi pemanfaatan hara tanaman, air dan cahaya,(2) memperkecil peluang serangan hama dan penyakit tanaman, (3) mengurangi resiko kegagalan panen, ketidakpastian dan fluktuasi harga, (4) pemeliharaan kebun lebih intensif, meningkatkan produktifitas lahan, (5) membantu percepatan peremajaan karet (petani tidak kehilangan sumber pendapatan), dan (6) mendistribusikan sumberdaya secara optimal dan merata sepanjang tahun serta menambah peluang lapangan kerja, termasuk tenaga kerja wanita. 
Kecukupan Air tidak menjadi faktor pembatas untuk pengembangan tanaman pangan sebagai tanaman sela karet, namun priode saat tanam dan panen harus disesuaikan dengan karakteristik hujan pada lokasi penanaman ini ditujukan untuk mendapat produksi yang optimal.

Modifikasi jarak tanaman karet dari jarak tunggal ke jarak tanam ganda merupakan salah satu solusi yang dapat diterapkan pada kendala naungan akibat tajuk tanaman karet dalam pengembangan jagung sebagai tanaman sela.

Kendala tanah masam dapat diatasi dengan menggunakan varietas jagung toleran tanah masam dan kekeringan serta disertai perbaikan kesuburan tanah melalui ameloirasi dengan kapur (dolomit atau kalsit) dan bahan organik serta melakukan pemupukan N,P,K yang optimal serta pemberian pupuk daun menjadi pilihan untuk mengatasi kekurangan hara mikro pada tanah. Untuk mendapatkan hasil yang optimal kunci utamanya adalah penggunaan varietas jagung yang toleran terhadap lahan kering dan masam.

\section{KESIMPULAN}

Memanfaatkan lahan dengan menanam tanaman sela jagung pada perkebunan karet (TBM) selain mengoptimalkan produktivitas lahan perkebunan karet sekaligus menambah pendapatan petani selama tanaman karet belum berproduksi.

Pemilihan varietas toleran lahan masam dan kekeringan merupakan kunci utama dalam mendapatkan prouksi yang optimal, kendala tanah masam dapat diatasi dengan pemberian kapur, pupuk organik dan $\mathrm{M}, \mathrm{P}, \mathrm{K}$, kendala intensitas cahaya akibat tajuk tanaman karet dapat diatasi dengan menerapkan pola tanaman ganda. 


\section{REFERENSI}

Ferry Y, Pranowo D dan Rusli Pengaruh Tanaman Sela Terhadap Pertumbuhan Tanaman Karet Muda Pada Sistem Penebangan Bertahap [Jurnal]. - Sukabumi : [s.n.], 2013. - hal. 229.

Herlina 2011 dalam Surtinah; Susi, $\mathbf{N}$; Lestari, S, U OPTIMASI LAHAN DENGAN SISTEM TUMPANG SARI JAGUNG MANIS (Zea mays saccharata, Sturt) DAN KANGKUNG SUTRA (Ipomea reptans) DI PEKANBARU [Jurnal] // Artikel Program Pasca Sarjana Universitas Andalas. - Pekanbaru : [s.n.].

Sitompul S M dan B Gurtino Analisis Pertumbuhan Tanaman [Jurnal]. - Yogyakarta : Gadjah Mada University Press, 1995.

Suriadikarta, Ardi, Simanungkalit dalam Susi, N; Surtinah; Rizal, M. Pengujian Kandungan Unsur Hara Pupuk Orgnik Cair (pPOC) Limbah Kulit Nenas [Jurnal] // Jurnal Ilmiah Pertanian. - Pekanbaru : [s.n.], Februari 2018. - Vol. 14 No 2.

Surtinah Agronomi Tanaman Budidaya [Buku]. - Pekanbaru : Alaf Riau, 2010. - hal. 80-81.

Surtinah dan Lidar, S. Pertumbuhan Vegetatif dan Kadar Gula Biji Jagung Manis (Zea mays saccharata, Sturt) di Pekanbaru [Jurnal] // J.IImiah Pertanian. - Pekanbaru : [s.n.], 2012. - Vol. 13(2). hal. 73-78.

Sutoro, Soelaeman $\mathbf{Y}$ dan Iskandar Budidaya Tanaman Jagung [Buku]. - Bogor: Balai Penelitian Tanaman Pangan, 1998. 